\title{
Exercise and bone health across the lifespan
}

\author{
Lívia Santos $\cdot$ Kirsty Jayne Elliott-Sale $\cdot$ Craig Sale $\mathbb{C}$
}

Received: 28 March 2017 / Accepted: 10 October 2017 / Published online: 20 October 2017

(C) The Author(s) 2017. This article is an open access publication

\begin{abstract}
With ageing, bone tissue undergoes significant compositional, architectural and metabolic alterations potentially leading to osteoporosis. Osteoporosis is the most prevalent bone disorder, which is characterised by progressive bone weakening and an increased risk of fragility fractures. Although this metabolic disease is conventionally associated with ageing and menopause, the predisposing factors are thought to be established during childhood and adolescence. In light of this, exercise interventions implemented during maturation are likely to be highly beneficial as part of a long-term strategy to maximise peak bone mass and hence delay the onset of age- or menopause-related osteoporosis. This notion is supported by data on exercise interventions implemented during childhood and adolescence, which confirmed that weight-bearing activity, particularly if undertaken during peripubertal development, is capable of generating a significant osteogenic response leading to bone anabolism. Recent work on human ageing and epigenetics suggests that undertaking exercise after the fourth decade of life is still important, given the antiageing effect and health benefits provided, potentially occurring via a delay in telomere shortening and
\end{abstract}

L. Santos · K. J. Elliott-Sale · C. Sale $(\bowtie)$

Musculoskeletal Physiology Research Group, Sport, Health and Performance Enhancement Research Centre, School of Science and Technology, Nottingham Trent University, Nottingham NG11 8NS, UK

e-mail: Craig.sale@ntu.ac.uk modification of DNA methylation patterns associated with ageing. Exercise is among the primary modifiable factors capable of influencing bone health by preserving bone mass and strength, preventing the death of bone cells and anti-ageing action provided.

Keywords Exercise $\cdot$ Lifespan - Bone health $\cdot$ Bone adaptation $\cdot$ Bone ageing $\cdot$ Osteoporosis

\section{Introduction}

Ageing is accompanied by the loss of bone mass and strength, predisposing the skeleton to the onset of osteoporosis (Demontiero et al. 2012). Osteoporosis is a metabolic disorder prevalent in post-menopausal women, characterised by accentuated bone weakening, greater susceptibility to fragility fractures (Hernlund et al. 2013), but also higher mortality risks (Klop et al. 2017; Panula et al. 2011). Hip fractures and associated comorbidities in particular, are responsible for the increase in 1-year mortality risks by more than threefold when compared with those without a bone fracture (Klop et al. 2017; Panula et al. 2011).

Osteoporosis is estimated to affect 22 million women and 5.5 million men in the EU (Hernlund et al. 2013). In 2010, there were $3.5 \mathrm{M}$ osteoporotoic fractures reported in the EU; 620,000 hip fractures, 520,000 vertebral fractures, 560,000 forearm fractures 
and 1,800,000 other fractures (Hernlund et al. 2013). In the UK, $3.21 \mathrm{M}$ people, aged over 50 years, are living with osteoporosis, with more than 536,000 new fragility fractures occur every year (Svedbom et al. 2013). The prevalence of osteoporosis is expected to rise over the next decades by virtue of population ageing. One-third of the UK population is 50 years old or above, and current estimates suggest this age segment will grow from 21.6 million in 2010 to 26.2 million in 2025, corresponding to an increase of $21 \%$ (UK Office for National Statistics 2016).

Osteoporosis and other musculoskletal disorders, particularly osteoarthritis and bone trauma, are amongst the most common problems affecting the elderly and are a leading cause of physical disability (Gheno et al. 2012; Weinstein 2016). Limitations in mobility and independance are psychologically devastating and represent a huge economic challenge to the sustainability of health care systems (Gheno et al. 2012; Weinstein 2016). Exercise, nutrition and pharmacological interventions may help the management of age-related bone loss and osteoporosis. Certain types of exercise might result in improved bone strength even after menopause, a time when bone mass declines and the ability to rescue lost bone is impaired (Polidoulis et al. 2011; Uusi-Rasi et al. 2003). With regard to nutrition, vitamin $\mathrm{D}$ is essential in calcium metabolism and oral intake may prevent fractures in osteoporotic patients (Lips et al. 2006). Pharmacological interventions are the gold standard with regards to osteoporosis management and prevention of fragility fractures, although their benefits are transient and might induce rare but severe side effects (Gozansky et al. 2005; Woo et al. 2006). Some of the concerns raised as a result of these side effects might well have contributed to the declining prescription of these drugs or the reduction in actual use of prescribed medications for low bone mass (Jha et al. 2015).

Exercise is one of the primary modifiable factors associated with improved bone health outcomes, such as high bone mineral density (BMD) and strength (Weaver et al. 2016). Individuals who undertake exercise on a regular basis are also more likely to prevent age-relate bone loss and experience fewer falls and fractures by virtue of developing stronger muscles and bones, which improve balance (Liu-Ambrose et al. 2004). In addition to this, exercise may provide a "rejuvenating effect" and, as a result, the potential to mitigate age-related bone loss and diseases (Loprinzi et al. 2015). In this article, we review the benefits of undertaking exercise throughout life as part of a strategy to promote bone health across the lifespan, and advance some cellular and molecular mechanisms potentially activated upon exercise that underpin such benefits. We will also highlight some areas where the clinical benefits of exercise on bone health might have been slightly exaggerated, given that increases in bone mass as a result of exercise are typically in the range of $1-10 \%$ at the most and reductions in bone mass across the lifespan are significantly greater (Riggs et al. 2004).

Bone and muscle are the two largest tissues of the musculoskeletal system and they are coupled mechanically, biochemically and molecularly (Brotto and Bonewald 2015), with muscular contraction thought to be the main source of mechanical strain leading to bone adaptation (Bakker et al. 2001; Burr 1997). Bone and muscle mass/strength are proportionally related, as evidenced by a study showing that under disuse conditions, muscle mass declines followed by a loss of bone mass, while during recovery muscle mass gains precede bone accretion (Sievänen et al. 1996). Although coupling between the two tissues and further interactions with other elements of the musculoskeletal system, particularly tendons, ligaments and cartilage is unquestionable, particularly in relation to the prevention of falls (perhaps the major contributor to bone fracture), this is beyond the scope of the present review.

\section{Ageing and bone loss}

\section{Ageing}

Ageing is a physiological process that results from the accumulation of molecular and cellular damage over time (WHO 2015). It is influenced by the human genome and epigenetic changes triggered by environmental and lifestyle factors (Govindaraju et al. 2015). Human ageing is generally accompanied by a decline of cognitive and motor functions (Moustafa 2014) and is considered the main risk factor for developing musculoskeletal, neurodegenerative and cardiovascular diseases (Niccoli and Partridge 2012). Genetic studies on progeroid syndromes, clinical conditions of premature ageing, have been useful to understand physiological ageing and age-related diseases (Martin 
and Junko 2010). Research on Hutchison-Gilford and Werner progeroid syndromes, in particular, have allowed the identification of several hallmarks of physiological ageing, such as telomere shortening, mitochondrial dysfunction, oxidative stress and cell senescence (Childs et al. 2015; López-Otín et al. 2013). Briefly, telomeres are protective caps located at the end of chromosomes with the purpose of preventing deterioration or fusion with other chromosomes. Telomere shortening exacerbates human ageing, as well as inducing metabolic alterations, such as insulin resistance, $\beta$-cell failure and glucose intolerance (Gardner et al. 2005; Shimizu et al. 2014). The mitochondria are organelles that generate the majority of the chemical energy utilised by cells, adenosine triphosphate (ATP). Mitochondrial dysfunction is caused by depletion of nicotinamide adenine dinucleotide (NAD+) and downregulation of the tricarboxylic acid and oxidative phosphorylation (OXPHOS) pathways (Zhang et al. 2016), leading to a decline in respiratory function and stem cell senescence (Wiley et al. 2016; Zhang et al. 2016). Senescent cells exhibit stress-induced permanent proliferative arrest and are thought to drive ageing and age-related pathologies (Baker et al. 2016; Childs et al. 2015). While in proliferative arrest, senescent cells secrete specific proteins, referred to as the senescence-associated secretory phenotype (SASP), which can exacerbate the proliferative arrest and also induce senescence in a paracrine manner. Interestingly, recent evidence came to light showing that the SASP can also exert a proregenerative effect through cell plasticity and stemness (Ritschka et al. 2017). Lastly, excessive or persistent oxidative stress caused by the action of free radicals, non-ionising radiation and inflammatory agents, and from mitochondrial byproducts (e.g., peroxides), was proposed to contribute to accumulated DNA damage and activation of apoptotic signalling pathways, potentially accelerating ageing (Kryston et al. 2011; Lu et al. 2012). Oxidative stress was identified as an important driver of bone ageing. This marker will be further discussed in the next section (Ambrogini et al. 2010; Manolagas 2010).

Age-related bone loss

Bone accretion occurs from birth and throughout childhood and adolescence, with approximately $90 \%$ of bone mass acquired by the age of 20 years (Henry et al. 2004; Recker et al. 1992). Acquisition of bone mass follows sex and age specific patterns, as evidenced in Fig. 1. Men have greater BMD than women and this difference becomes starker as sexual maturation progresses (Hendrickx et al. 2015). When women reach late 30 s and men early 40s, BMD starts to decline and this trend persists throughout life (Fig. 1). Such decline is further accompanied by a decrease in bone strength strength (Wall et al. 1979), osteocyte death, deteoration of type I collagen (Bailey and Knott 1999) and adipogenesis at the expense of osteogenesis (Justesen et al. 2001). Age-related bone loss occurs due to greater bone resorption than bone formation, a process that culminates in reduced trabecular volume and diminished cortical bone width (McCalden et al. 1993). For a comprehensive review of these changes see (Boskey and Coleman 2010; Manolagas and Parfitt 2010).

Oxidative stress has been identified as a critical driver of bone ageing (Ambrogini et al. 2010; Manolagas 2010). Production of mitochondrial superoxide anion $\left(\mathrm{O}_{2}{ }^{-}\right)$in aged osteocytes led to increased osteoclast-mediated bone resorption (Kobayashi et al. 2015). In addition to this, the presence of reactive oxygen species (ROS) has been shown to attenuate $\beta$ catenin signalling with concomitant activation of $\operatorname{PPAR} \gamma$ favouring adipogenesis at the expense of osteoblastogenesis and bone formation (Manolagas 2010). The loss of function of oxidative defense Forkhead box O (FOXOs), a family of genes implicated in ageing and longevity, triggers the apoptosis of osteoblasts and osteocytes and the advance of an osteoporotic phenotype (Ambrogini et al. 2010). In this same study, the authors showed that an overexpression of FOXO3 in osteoblasts culminated in increased bone mass. These findings demonstrate that signalling pathways implicated in bone cell survival and osteogenesis are negatively affected by oxidative stress leading to age-related bone loss and potentially osteoporosis.

\section{The osteoporotic bone}

Osteoporosis is the most prevalent disease in postmenopausal women and is accompanied by an increased risk of fragility fractures (Ji and Yu 2015). Fragility fractures occur primarily in the spine, hip and 
Fig. 1 Bone mass density (BMD) across the lifespan. Men exhibit higher BMDs throughout life and are less susceptible to age-related bone loss than women. Adapted from Hendrickx et al. (2015)

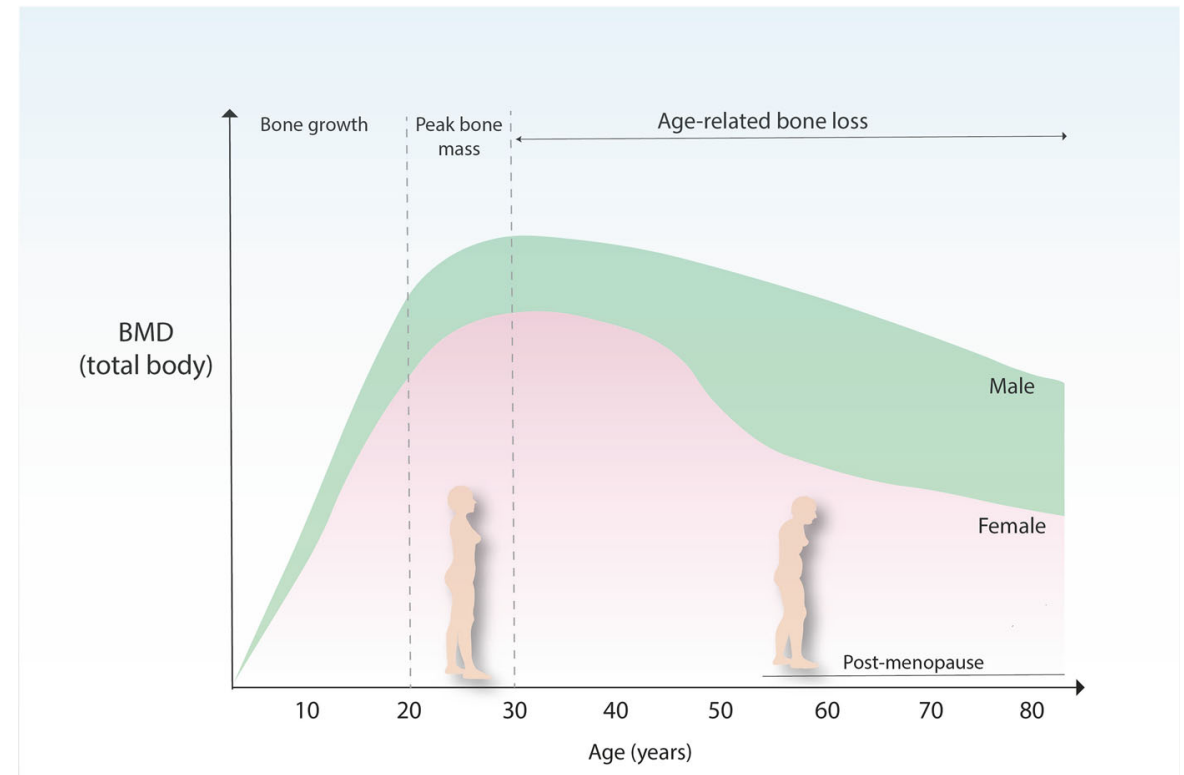

wrist (NICE 2012). Hip fractures cause permanent disability in $50 \%$ of the cases and death in $20 \%$ (Sernbo and Johnell 1993). In the UK, 300,000 fragility fractures occur every year (British Orthopaedic Association 2007), with direct medical costs estimated at $£ 1.8$ billion in 2000 and projected to reach $£ 2.2$ billion by 2025 (Burge et al. 2001).

Osteoporosis arises from the imbalance between bone resorption (osteoclast-mediated) and bone formation (osteoblast-mediated), with bone resorption exceeding bone formation. At histopathological level, the osteoporotic bone is less compact as a result of bone thining or loss, presents a strong reduction in the trabecular connectivity and greater adiposity of the bone marrow (Marcu et al. 2011).

Oxidative stress and oestrogen depletion are two important mechanisms underpinning osteoporosis. Oxidative stress was reported to direct commitment of mesenchymal progenitors towards the adipogenic lineage at the expense of osteoblastogenesis (Manolagas 2010), which can explain greater adipodicity of the bone marrow in old and osteroporotic bone (Justesen et al. 2001). Oestrogen has a protective role in bone health e.g., by controlling bone resorption activity. This was demonstrated by studies evidencing that oestrogen inhibits osteoclast formation and activity via increased production of osteoprotegerin (Hofbauer et al. 1999) or transforming growth factor $\beta$ (Hofbauer et al. 1999; Hughes et al. 1996), and may also induce apoptosis of osteoclast progenitor cells via blocking of the cytokine receptor activator of $\mathrm{NF \kappa B}$ ligand (RANKL) (Lundberg et al. 2001). Oestrogen action on bone resorption activity was further confirmed by a study showing that selective deletion of the oestrogen receptor- $\alpha(\mathrm{ER} \alpha)$ in osteoclast lineage cells increased osteoclastogenesis activity and abrogated the oestrogen-mediated pro-apoptotic action in osteoclasts (Almeida et al. 2013). These changes led to increased bone resorption in women, but not in men, causing a loss of cancellous, but not cortical, bone (Almeida et al. 2013). When oestrogen is depleted in the organism, e.g., post-menopause, this protective effect on bone health is reduced or disappears and this increases predisposition to the onset of bone diseases like osteoporosis.

Osteoporosis is conventionally appraised by dualenergy X-ray absorptiometry (DXA) and the resultant BMD values are compared to the BMD of young healthy individuals of the same gender, thus generating a $T$ score. A $T$ score of -1 and above is considered normal, a score between -1 and -2.5 is indicative of osteopenia, and a score of -2.5 or below signifies osteoporosis. This categorisation was established by the Word Health Organisation (WHO) to standardise the diagnosis of oesteoporosis, particularly in Caucasian, postmenopausal women. BMD values can also 
be compared to the BMD of age-matched individuals with normal bone mass to generate a $Z$ score. $Z$ Scores are mostly utilised in cases of severe osteoporosis. BMD is, however, only one element of bone strength, with areal BMD (aBMD) accounting for $65-75 \%$ of the variance in bone strength. As such, there is a need to also consider volumetric BMD, bone geometry and bone architecture.

According to the severity of bone loss, the presence of fragility fractures and other clinical factors, patients may be prescribed with anti-osteoporotic drugs, primarily the oral intake of bisphosphonates, such as alendronate. Third generation (nitrogen-containing) alendronate binds to bone mineral and is metabolised by osteoclasts leading to the inhibition of bone resorptive activities and an increase of bone strength (Boivin et al. 2000). Another important anti-bone resorption drug is strontium ranelate, although its mechanism of action differs from bisphosphonates by targeting bone formation and mineralisation directly, rather than by suppressing osteoclast-mediated bone resorption activity (Marie 2007). Denosumab is a human monoclonal antibody that binds to RANKL, inhibiting it. RANKL suppression impairs osteoclast maturation and survival leading to the diminution of bone resorption activity (Hanley et al. 2012). The teriparatide human recombinant parathyroid hormone (hrPTH), is clinically approved for the treatment of osteoporosis due to its anabolic effect on bone and its ability to rescue skeleton strength (Pazianas 2015). The use of hrPTH is recommended for up to 24 months and has been shown to reduce fracture risks (Lindsay et al. 2016; Neer et al. 2001).

The prescription of anti-osteoporotic drugs is vital for the management of osteoporosis and its related comorbidities, although they are not always effective and the benefits are transient (Gozansky et al. 2005). Gozansky et al. (2005) investigated the efficacy of oestrogen and raloxifene in conserving BMD during a 6-month exercise-based weight loss program (Gozansky et al. 2005), where participants were allowed to select the mode(s) of exercise e.g., treadmill, walking/ running, cycling, among others. The authors showed that both pharmacological interventions failed to maintain intact lumbar spine, total hip and trochanter BMD in post-menopausal women enrolled in a lost weight program, although BMD losses were more pronounced in women belonging to the placebo group
(Gozansky et al. 2005). With regard to side effects, long-term use of bisphosphonates can cause severe collateral damage, such as jaw necrosis (Woo et al. 2006). In light of this, it has been advocated that regular exercise might be one of the best nonpharmacological approaches to support bone health across the lifespan (Gomez-Cabello et al. 2012), either by maximising peak bone mass during maturation, delaying the onset of osteoporosis later in life (Tveit et al. 2015; Warden et al. 2007) and/or by mitigating the age and/or menopausal-related bone loss (Howe et al. 2011; Polidoulis et al. 2011). Much of the evidence in support of a positive effect of exercise on bone is, however, observational and many of the direct exercise intervention studies have not shown such large effects on bone. Over the next sections the influence of exercise on age-related bone loss and osteoporosis will be discussed.

\section{Bone remodelling and adaptation to exercise}

Bone is a heterogeneous tissue made up of two components, an organic part comprised of collagenous and non-collagenous proteins and cells and a mineral component of hydroxyapatite (Boskey 2013). Bone contains three major cell types: osteoblasts, which derive from mesenchymal stem cells and are responsible for bone formation; osteocytes, dendritic cells terminally differentiated from osteoblasts embedded in the bone matrix, accounting for more than $90 \%$ of bone cells; and osteoclasts, large multinucleated cells differentiated from hematopoietic progenitor cells that mediate bone resorption (Schaffler et al. 2014; Tatsumi et al. 2007). The coordinated action of osteoblasts, osteoclasts and osteocytes orchestrate bone modelling and remodelling. Bone modelling occurs to accommodate the radial and longitudinal growth of bone during the growing years and to adapt the skeleton to mechanical strain, whereas remodelling happens mainly during adulthood to remove microdamaged and old bone, adapt bone tissue to mechanical loading and maintain the strength and integrity of the skeleton (Sims and Martin 2014). During modelling, osteoclastogenesis and osteogenesis work independently, whereas in remodelling, bone resorption and formation are coupled, taking place in bone remodelling units (Baron and Kneissel 2013). 
Bone adaptation to exercise

Exercise leads to bone adaptation and this process is mediated by cellular mechanotransduction (Goodman et al. 2015). Briefly, upon exercise, bone tissue deforms, and the mechanosensors located throughout the cells, such as stretch-activated ion channels and integrins, change their original conformation (Guilluy et al. 2014; Ross et al. 2013). Such conformational changes trigger a signalling cascade to provide an appropriate biochemical response (Goodman et al. 2015), e.g., osteogenesis and bone accretion at the site of deformation.

Osteocytes are mechanotransduction hot spots due to their unique ability to detect and respond to mechanical strains (Klein-Nulend and Bakker 2007). Osteocytes control bone formation and resorption through the differentiation of osteoblasts and osteoclasts and by stimulating the expression of the osteoclastogenesis inhibitor, osteoprotegerin (Regard et al. 2012). Osteoblasts also secrete osteoprotegerin evidencing that this cell type also presents the potential to regulate bone resorption activity (Udagawa et al. 2000).

Of critical importance is the osteocyte's ability to mediate the anabolic actions of the $\mathrm{Wnt} / \beta$-catenin signalling pathway ( $\mathrm{Tu}$ et al. 2015). This signalling pathway is evolutionarily conserved and can be categorised into three forms: an inactive form, where $\beta$-catenin is phosphorylated and degraded by ubiquitination in the proteasome, and two active forms, termed as canonical or non-canonical (Fig. 2). It is activated upon mechanical loading e.g., generated from exercise to initiate osteogenesis and bone formation (Krishnan et al. 2006), either by direct stimulation of the bone transcription factor RUNX2 (Gaur et al. 2005) or by crosstalking with PTH or morphogenetic proteins (BMPs) signalling pathways (Baron and Kneissel 2013; Gardinier et al. 2016). A recent investigation showed that circulating PTH, generated from physical activity, led to downregulation of sclerostin (an anti-anabolic bone protein) in osteocytes (Gardinier et al. 2016) was accompanied by significant upregulation of fibroblast growth factor-23 (FGF-23) expression (Gardinier et al. 2016), a growth factor governing phosphatase homoeostasis and vitamin D metabolism (Quarles 2012). Collectively, these findings demostrate the vital role of osteocyte Wnt/ $\beta$ catenin signalling in the bone adaptation to exercise.

Exercise could be a means to maintain or enhance a specific health outcome, such as maximising bone accretion and/or improving bone strength. Bone adaptation to exercise is initiated by muscle contraction and ground-reaction forces (Sharkey et al. 1995). Bone traits, such as BMD, strength and architecture, change and adapt to help the skeleton to cope with the loading environment while preventing injuries. To illustrate the bone adaptation response, athletes undertaking intermittent high impact exercise (Olympic fencers as just one example) exhibit higher densities of cortical and trabecular bone than matched controls (Chang et al. 2009). Similarly, in athlete groups where a highly active limb can be compared to a less active limb, such as the racket arm versus non-racket arm of tennis players (Haapasalo et al. 2000; Ireland et al. 2013) or in the throwing arm vs non-throwing arm of baseball players (Warden et al. 2014), there is a greater bone mass observed in the more active limb. Conversely, 6-months of spaceflight results in a $10 \%$ loss in the BMD of astronauts living under zero gravity conditions, where gravitational mechanical loading and, therefore, ground-reaction forces are missing ( $\mathrm{Si}$ bonga 2013).

Upon beginning exercise, the skeleton is exposed to different types of strains (deformation of tissue) generated from compression, tensile and torsional forces, and shear stress. Diferent types of strains can occur at the same time and in the same bone (Judex et al. 2009). In this study, a compression strain occurred at $2500 \mu$ s on one side of the bone and a tensile strain of $2000 \mu$ s on the other side. It is also established that running generates tibial strains 2-3 times higher than walking (Burr et al. 1996) and walking higher than cycling (Milgrom et al. 2000). The optimal magnitude and frequency to initiate an osteogenic response in humans is still uncertain as most studies are undertaken in animals. On the other side, the optimal exercise to induce osteogenesis and bone anabolism is likely to change according to age, sex, the individual (Weaver et al. 2016) and even skeletal site, suggesting that only a personalised approach would provide the precision information to design the optimal osteogenic exercise regimen. 


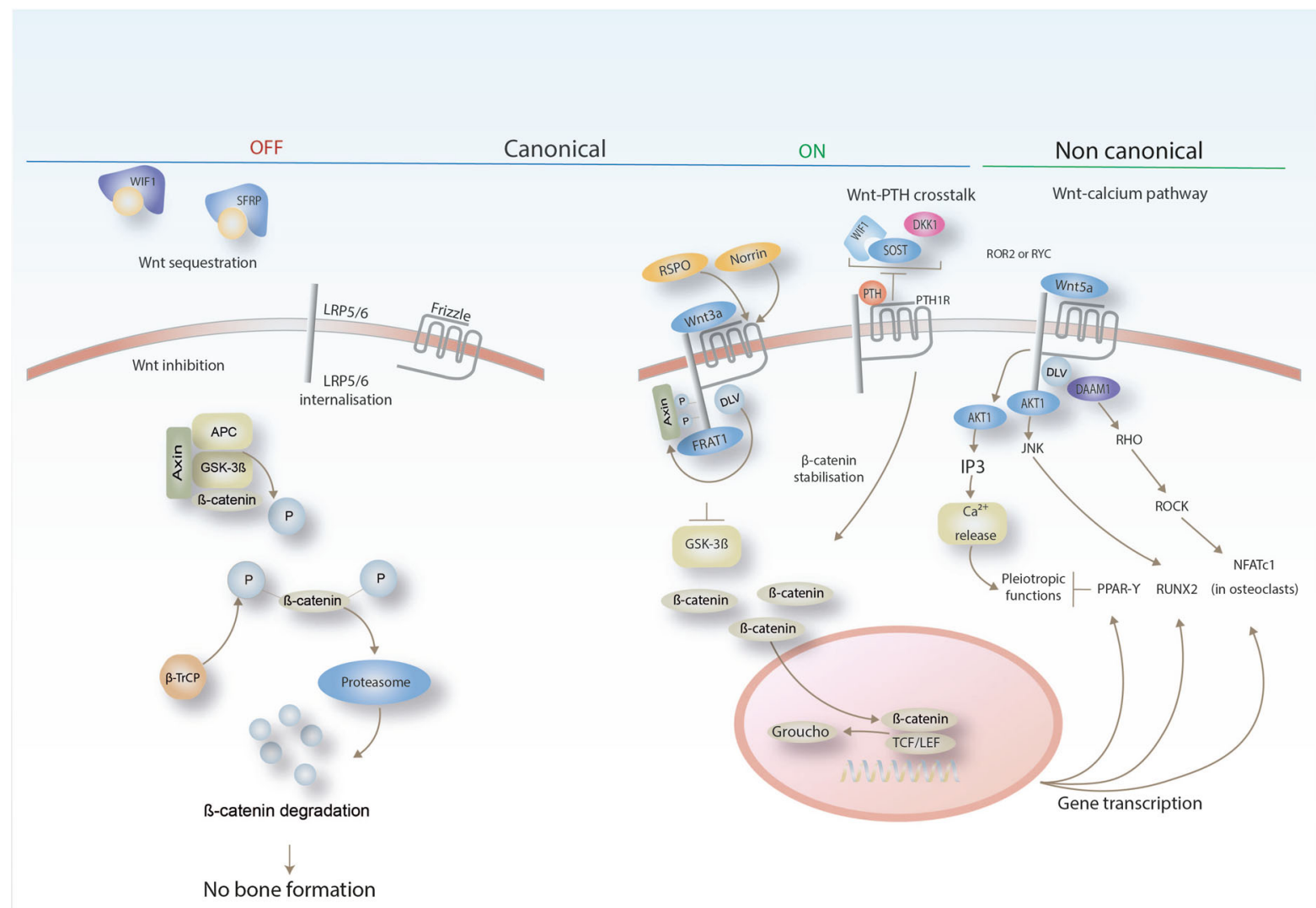

Fig. 2 Simplified diagram depicting canonical and non canonical $\beta$-catenin signalling pathways in bone. Exercise enables bone formation through the active canonical and non-canonical $\beta$-catenin signalling pathways. Activation of the bone transcription factor RUNX2 elicits osteogenesis and supresses PPAR- $\gamma$ mediated adipogenesis; Activation of WIF1: Wnt Inhibitory Factor 1: SFRP: Secreted frizzled-related protein; LRP5/6: Low-density lipoprotein receptor-related protein 5/6; APC: adenomatous polyposis coli; GSK-3 $\beta$ : glycogen synthase kinase 3 beta; Ub: ubiquitination; P: phosphorylation; $\beta$-TrCP: betatransducin repeat containing E3 ubiquitin protein ligase; RSPO: R-spondin 1; WNT3A: Wnt family member 3A; FRAT1: FRAT1, WNT signalling pathway regulator; DVL: dishevelled

\section{Bone adaption to exercise across the lifespan}

Exercise interventions during childhood and adolescence

The promotion of physical exercise and healthy eating habits during bone development maximises the chances of accruing bone, potentially delaying the onset of osteoporosis in later life. Such a perspective is supported by longitudinal studies showing that individuals who were active during childhood had $8-10 \%$ segment polarity protein 1; TCF/LEF: T cell factor/lymphoid enhancer factor; DKK1: Dickkopf Wnt Signaling Pathway Inhibitor 1; PTH: Parathyroid hormone; PTH1R: Parathyroid hormone 1 receptor; SOST: Sclerostin; ROR2: receptor tyrosine kinase like orphan receptor 2; RYK: receptor-like tyrosine kinase; WNT5A: Wnt family member 5A; AKT1: AKT serine/ threonine kinase 1; IP3: Inositol trisphosphate; DAAM1: Disheveled-associated activator of morphogenesis 1; JNK: c-Jun N-terminal kinases; ROCK: Rho-associated protein kinase; NFATc1: Nuclear factor of activated T-cells, cytoplasmic 1; PPAR- $\gamma$ : Peroxisome proliferator-activated receptor gamma; RUNX2: Runt-related transcription factor 2. Adapted from Baron and Kneissel (2013)

greater hip bone mineral content (BMC) in adulthood (age 23-30 years) than their sedentary counterparts (Baxter-Jones et al. 2008). A more recent longitudinal trial showed that children engaged in school-based exercise interventions for 9 months had higher wholebody $(6.2 \%)$, femoral neck $(8.1 \%)$ and total hip $(7.7 \%)$ BMC compared with their non-exercising counterparts (Meyer et al. 2013). Three years after ceasing the intervention, the benefits persisted, with a sustained $7-8 \%$ increment of BMC in the femoral neck and total hip of conditioned individuals (Meyer et al. 2013). A 
cross-sectional study investigating the long-term benefits of performing upper body exercise (ball throwing) suggested that half of the benefit in bone size and one-third of the benefit in bone strength was kept throughout life (Warden et al. 2014). Tveit et al. (2015) conducted a cross-sectional, cohort study investigating the long-term, 30 years after retirement, effects of soccer on BMD, bone structure and fracture risk. They showed that exercise generated higher BMD's, larger bones and a lower fracture risk in former athletes after retirement (Tveit et al. 2015).

Peak bone mass (PBM) is regarded as a significant predictor of future osteoporosis and fracture risk (Specker et al. 2010). Bioinformatics' and metaanalyses calculations have estimated that a $10 \%$ increase in PBM would delay the onset of osteoporosis by 13 years (Hernandez et al. 2003) and reduce fracture risk, resulting from osteoporosis, by up to $50 \%$ in post-menopausal women (Marshall et al. 1996). A $6.4 \%$ decrease in bone mass in childhood has been associated with a twofold increase fracture risk during adulthood (Boreham and McKay 2011). This evidence suggests that exercise interventions, spanning childhood and adolescence, are effective, even after the activity has ceased, although the timing of initiation may be important. An interesting recent study has also suggested that the age at which children first start walking might influence their bone strength in later life (Ireland et al. 2017). Ireland et al. (2017) examined the association betweent walking age (obtained at 2 years old) and bone outcomes determined by DXA and pQCT (between the ages of 60 and 64 years old). Later independent walking age was associated with lower height-adjusted hip, spine and distal radius BMC in men, suggesting that the ability to mechanically load the skeleton early during bone development might be important in the development of good bone health.

A systematic review addressing bone mineral changes in response to weight-bearing exercise (e.g., ball games dancing, jumping, and others) proposed that bone adaptations peak during early puberty (MacKelvie et al. 2002). More specifically, they showed that weight-bearing exercise during childhood had a positive effect on bone strength, while exercise undertaken during prepubertal and peripubertal ages caused an increment in bone mineral accrual (MacKelvie et al. 2002). These findings were reinforced by a subsequent systematic review that analysed bone mineral accrual in children and adolescents (Hind and Burrows 2007). Despite osteogenesis and bone anabolism being more pronounced during the peripubertal stage, the ideal modality or training regimen to optimise bone mass accrual remains to be elucidated.

Exercise interventions during adulthood

Adults might also also benefit from bone-loading exercise, but systematic reviews and meta-analyses on the topic (Bolam et al. 2015; Hamilton et al. 2010; Martyn-St James and Carroll 2010) suggest that this might occur to a lesser extent than in children and adolescents (Hind and Burrows, 2007; Nogueira et al. 2014). Nonetheless, Heinonen et al. showed that premenopausal women, aged 35-45 years, who performed a high-impact exercise regimen, consisting of jump and step training for 18-months, had progressive increases in BMD at the femoral neck (a load bearing site) when compared with inactive controls (Heinonen et al. 1996). A meta-analysis, of randomised controlled exercise trials lasting 24 weeks, also showed improvements in femoral neck and lumbar spine BMD (Kelley et al. 2013). Bassey et al. (1998) examined bone accrual after a 12-month exercise training intervention in both pre- and postmenopausal women. Training consisted of vertical jumping, 6 times per week, and resulted in a $2.8 \%$ increase in femoral BMD in pre-menopausal women, whereas no improvements were shown in postmenopausal women after 12- or 18-months of training and hormone replacement therapy (Bassey et al. 1998). The inability of post-menopausal women to accrue bone mass after high impact training was later confirmed by a 12-month randomised controlled trial on the effect of weight-bearing jumping and oral alendronate, alone or in combination, on bone mass and structure (Uusi-Rasi et al. 2003). Exercise alone or in combination with alendronate had no effect on bone mass at the femoral neck or lumbar spine (Uusi-Rasi et al. 2003). The "anabolic resistance" to exercise shown in post-menopausal women likely results, at least in part, from depleted oestrogen levels ( $\mathrm{Ji}$ and $\mathrm{Yu}$ 2015). Oestrogen is a pleiotropic hormone, with a vital role in skeletal growth and bone homoeostasis, as well as in sexual dimorphism and reproduction (Weitzmann and Pacifici 2006). All bone cells have oestrogen receptors and when circulating levels of oestrogen drop, Wnt/ $\beta$-catenin and the oestrogen ER $\beta / G S K-3 \beta$ - 
dependent signalling pathways are attenuated, leading to reduced osteoblastic proliferation (Yin et al. 2015). Attenuation of these signalling pathways, with concomitant diminished osteoblastic proliferation, is thought to cause the lack of responsiveness of postmenopausal women to bone-loading exercises (Yin et al. 2015).

Although these studies have shown that osteogenic and bone anabolic effects, resulting from exercise, are less pronounced or are even negligible when coupled with oestrogen depletion, post-menopausal women are strongly advised to undertake exercise. Exercise, of the right type, might well contribute to BMD preservation, presumably by maintaining cortical and trabecular volumetric BMD (Polidoulis et al. 2011), and by contributing to bone strength by means of cortical bone thickening (Uusi-Rasi et al. 2003). Among the exercise modalities tested in this population, walking provided modest benefits, due to the minor mechanical load exerted on the skeleton, while resistance and multi-component exercise programmes, encompassing strength, aerobic, and whole-body vibration exercises, were more effective in mitigating the loss of bone mass (Gomez-Cabello et al. 2012).

\section{Exercise interventions during older age}

Studies investigating exercise on bone health in older people (50s and above) are scarce. A comparative study, which enrolled men and women in their early 50 s, demonstrated that after 24 weeks of moderate strength or high intensity training, men that undertook the high intensity program gained $1.9 \%$ BMD in the spine, while women did not (Maddalozzo and Snow 2000). Allison et al. (2015) conducted a 12 -month randomised controlled trial in male participants, aged 65-80 years, who performed unilateral hopping exercise, whilst the other leg remained as an inactive control. In this trial, computer tomography (CT) and DXA measurements demonstrated that unilateral hopping caused an increase in BMC in both legs, with the trained leg depicting localised changes in the proximal femur. Cortical BMC at the trochanter increased more in the exercising than in the control leg, which is thought to be important for the structural integrity of the bone (Allison et al. 2015). A similar training programme, carried out over 12-months in men aged 65-80 years, showed increased femoral neck BMD, BMC and geometry (Allison et al. 2013).
Exercise might contribute to bone health by augmenting bone mass and bone strength during younger age and by mitigating age-related bone loss. In practice, however, this statement might be an oversimplification, as there are undoubtedly several factors that mediate the effects of exercise on the bone. Current or previous habitual levels of exercise, exercise mode, type, intensity and duration will all have a significant influence on the magnitude of any effects on bone related outcomes. Recently, Ireland and Rittweger (2017) also suggested that participation motivation might also play a part in the success or failure of exercise interventions targeted at the bone (Ireland and Rittweger 2017), which is certainly an area worthy of consideration.

Although the cellular and molecular mechanisms underpinning bone outcomes are still under investigation, the role of the $\mathrm{Wnt} / \beta$-catenin signalling pathway both in bone health and as a target of anti-osteoporosis interventions is becoming increasing clear (Karasik et al. 2016; Korvala et al. 2012). It was reported that mechanical loading exerted on mesenchymal stem cells blocked adipogenic differentiation by rescuing $\beta$ catenin-FOXO mediated transcription to $\beta$-cateninTCF/LEF mediated transcription (Fig. 3) (Case et al. 2013). This result was corroborated by an in vivo study involving mice, which demonstrated that exercise suppressed the accumulation of fat in the bone marrow (Styner et al. 2014), except that in this case the authors hypothesised that $\beta$-oxidation was the underpinning mechanism. Another route by which exercise might mitigate age-related bone loss is through the prevention of osteocyte apoptosis (Fonseca et al. 2011; Mann et al. 2006). This was evidenced by research conducted with ovariectomized mice exposed to exercise activity and human bone explants exposed to mechanical tension, with both providing evidence that mechanical stimulation prevented osteocyte death (Fonseca et al. 2011; Mann et al. 2006), a fact that contributes to preservation of bone strength.

Exercise, besides supporting bone health outcomes such as BMD and bone strength, provides an antiageing effect by virtue of preventing telomere erosion (Fig. 3) (Loprinzi et al. 2015). A longitudinal study, of 6503 participants aged 20-84 years, showed that exercise interventions prevented or delayed telomere shortening, therefore exhibiting an "age-defying" or rejuvenating action (Loprinzi et al. 2015). This study suggested that (i) a dose-response relationship exists between exercise and reduced telomere erosion and 


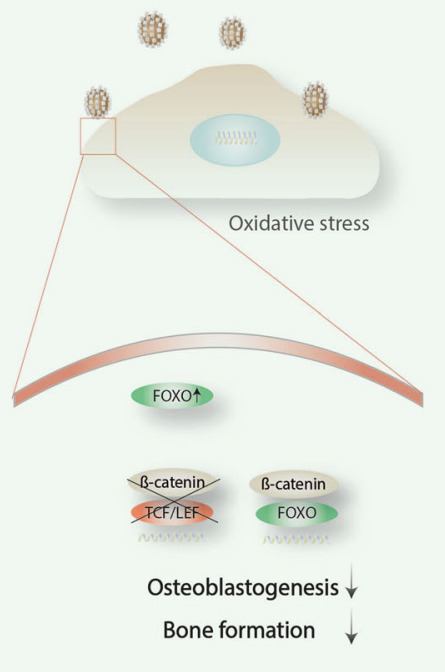

Osteopenia \& Osteopororis $\uparrow$

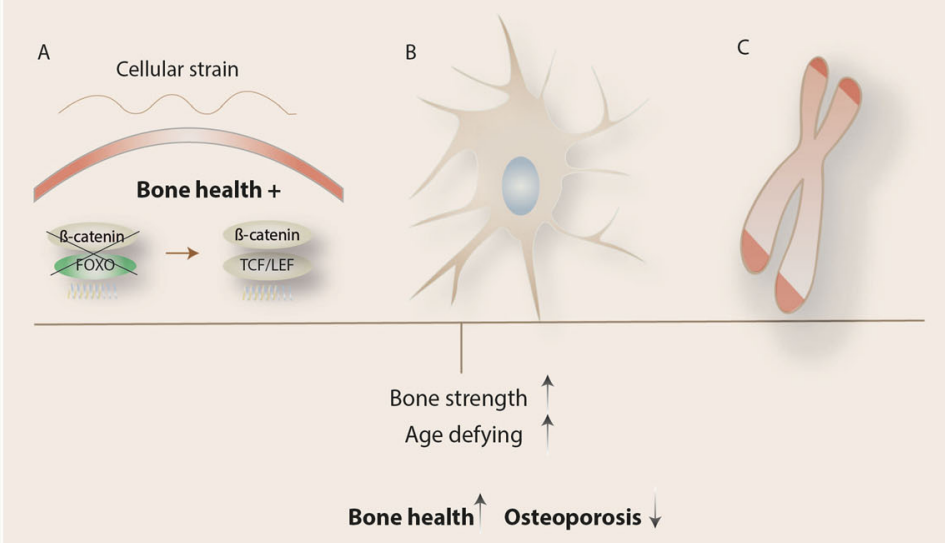

Fig. 3 Activation of FOXO transcription signalling upon oxidative stress (left) in the context of the aged bone; Rescue of TCF/LEF transcription (a), prevention of osteocyte apoptosis

(ii) this relationship was significant in participants aged 40-64 years. According to this, undertaking exercise after the fourth decade of life appears to improve systemic health on account of the counterageing effect provided. This systemic effect may mitigate ageing and accordingly age-related bone loss and age-related osteoporosis. Notably, individuals with osteoporosis exhibit shorter telomeres than healthy ones (Valdes et al. 2007), a fact that supports the notion that preventing or delaying systemic ageing is beneficial to bone health. Due to the progress of molecular biology, it is possible that bone health may also now be appraised by the assessment of telomere length given that leucocyte telomere shortening correlates with lower BMD at the lumbar spine, femoral neck and total hip (Nielsen et al. 2015).

Beside the mechanisms illustrated here, we acknowledge that exercise might contribute to bone health through other routes as, for example, changes in (b) and prevention of telomere erosion (c) induced by exercise potentially contribute to bone health

hormone levels or by targeting signalling pathways other than Wnt/ $\beta$-catenin signalling, such as the BMP or RANK/RANKL.

Exercise is also linked with epigenetic modifications, in particular, changes in DNA methylation patterns and gene expression (Brunet and Berger 2014; Jung and Pfeifer 2015; Rönn et al. 2013). DNA methylation is an epigenetic modification typically leading to long-term gene repression, achieved by the addition of a methyl group to the five position of a cytosine ring (Cedar and Bergman 2009). The relationship between exercise and DNA methylation was demonstrated in an epidemiological study comprising two groups; healthy volunteers and type II diabetics (Rönn et al. 2013). In this study, participants performed spinning and aerobic exercise over a 6-month period, with an average attendance of 1.8 times per week. DNA methylation changed in participants from both groups; more specifically in 7663 genes, one- 
third of which showed altered mRNA expression levels (Rönn et al. 2013). In another study, young sedentary participants of both sexes were exposed to acute bouts of exercise to ascertain whether acute exercise could change DNA methylation patterns. DNA was hypomethylated in skeletal muscle, in a dose-responsive fashion, with similar findings in mouse muscles 45 min after ex vivo contraction, both suggesting a putative role of exercise in epigenetic modification through DNA methylation (Barrès et al. 2012). The causal relationship between exercise and changes in DNA methylation was further corroborated by an investigation enrolling young male and female individuals in a 3-month fully supervised one-legged exercise training programme. Here, DNA methylation patterns changed in 4919 sites across the genome of the trained leg group (Lindholm et al. 2014). These epigenetic studies allowed identification of changes in DNA methylation patterns resulting from exercise on healthy, type II diabetic and young sedentary populations. To undertake similar studies in the older individual might reveal an age reversing epigenetic signature induced by exercise that might be utilised as a technique to asses not only bone health but also the effect of exercise in older individuals with chronic bone diseases.

\section{Conclusions}

Osteoporosis is a bone metabolic disease that prevails in post-menopausal women. The first line of treatment relies on anti-osteoporotic drugs, particularly bisphosphonates, although this type of therapy can only be provided for a limited period of time and the benefits are transient. Exercise has the potential to provide a means of non-pharmacological intervention, with long-lasting effects that can delay the onset of osteoporosis, particularly if performed during the peripubertal stage, a time during which exerciseinduced osteogenesis and bone anabolism is more accentuated. There are no current data, however, to directly compare appropriate exercise with pharmacological interventions designed to prevent bone loss or increase bone mass. These studies are urgently required to determine the extent to which exercise may or may not be able to provide a sole (highly unlikely) or adjunct therapeutic intervention against osteoporosis.
Exercise might be recommended following the menopause to mitigate the age- and menopausalrelated loss of bone and to strengthen cortical bone. During growth and development PBM should be maximised, with exercise potentially providing a means to help achieve this. During middle- and older-age, weight-bearing exercises should be performed to maintain bone mass and increase bone strength. It remains largely unknown, however, what the best type of exercise is in terms of mode, type, intensity and duration to maximise bone responses. It is likely that any exercise would need to be highintensity, high-impact, multidirectional and possibly unaccustomed in order to optimise osteogenic responses, but this approach might not be suitable for all.

Glossary

\begin{tabular}{|c|c|c|}
\hline & Acronym & Definition \\
\hline $\begin{array}{l}\text { Dual-energy } \\
\text { X-ray } \\
\text { absorptiometry }\end{array}$ & DXA & $\begin{array}{l}\text { Standard methods to measure } \\
\text { BMD. Two X-ray beams with } \\
\text { different energy levels are } \\
\text { conveyed to the patient's } \\
\text { bone. After subtracting the } \\
\text { signal from soft tissue, the } \\
\text { obtained absorption values } \\
\text { allow to estimate bone BMD }\end{array}$ \\
\hline $\begin{array}{l}\text { Computed } \\
\text { tomography }\end{array}$ & CT & $\begin{array}{l}\text { Imagining technique that } \\
\text { allows obtaining detailed } \\
\text { scans of areas inside the body }\end{array}$ \\
\hline $\begin{array}{l}\text { Bone mineral } \\
\text { density }\end{array}$ & BMD & $\begin{array}{l}\text { Refers to the amount of mineral } \\
\text { matter per square centimetre } \\
\text { of bone. BMD is utilised as } \\
\text { predictor of osteoporosis and } \\
\text { fracture risk. Parameter } \\
\text { utilised to estimate bone } \\
\text { strength }\end{array}$ \\
\hline
\end{tabular}

Aerial bone aBMD It is a reasonable estimate of mineral density $\quad \mathrm{BMC}$ and bone strength, not an accurate measurement of true bone mineral density, which is mass divided by volume. Parameter utilised to estimate bone strength

Bone mineral BMC $\begin{gathered}\text { Estimated by DXA, these } \\ \text { measurements reflect BMD at } \\ \text { specific body parts, spine, hip, } \\ \text { wrist, femur or other selected } \\ \text { part of the skeleton. The } \\ \text { values obtained are divided } \\ \text { by the surface area of the bone } \\ \text { being measure to create BMD }\end{gathered}$




\begin{tabular}{lll}
\hline & Acronym & Definition \\
\hline Peak bone mass & PBM & $\begin{array}{c}\text { Amount of bone gained by the } \\
\text { time a stable skeletal state has } \\
\text { been attained. At a population } \\
\text { level, peak bone mass reflects } \\
\text { the maximum bone mass } \\
\text { attained across the lifespan. It } \\
\text { is a predictor of osteoporosis }\end{array}$ \\
$\begin{array}{ccc}\text { Volumetric peak } \\
\text { bone mass }\end{array}$ & vPBM & $\begin{array}{c}\text { Refers the amount of peak bone } \\
\text { mineral content per cubic } \\
\text { centimetre of bone }\end{array}$ \\
\hline
\end{tabular}

Open Access This article is distributed under the terms of the Creative Commons Attribution 4.0 International License (http://creativecommons.org/ licenses/by/4.0/), which permits unrestricted use, distribution, and reproduction in any medium, provided you give appropriate credit to the original author(s) and the source, provide a link to the Creative Commons license, and indicate if changes were made.

\section{References}

Allison SJ, Folland JP, Rennie WJ, Summers GD, BrookeWavell K (2013) High impact exercise increased femoral neck bone mineral density in older men: a randomised unilateral intervention. Bone 53(2):321-328. doi:10.1016/ j.bone.2012.12.045

Allison SJ, Poole KES, Treece GM, Gee AH, Tonkin C, Rennie WJ, Brooke-Wavell K (2015) The influence of high-impact exercise on cortical and trabecular bone mineral content and 3D distribution across the proximal femur in older men: a randomized controlled unilateral intervention. J Bone Miner Res 30(9):1709-1716. doi:10. 1002/jbmr.2499

Almeida M, Iyer S, Martin-Millan M, Bartell SM, Han L, Ambrogini E, Manolagas SC (2013) Estrogen receptoralpha signaling in osteoblast progenitors stimulates cortical bone accrual. J Clin Investig 123(1):394-404. doi:10. 1172/JCI65910

Ambrogini E, Almeida M, Martin-Millan M, Paik J, DePinho RA, Han L, Manolagas SC (2010) FoxO-mediated defense against oxidative stress in osteoblasts is indispensable for skeletal homeostasis in mice. Cell Metab 11(2):136-146. doi:10.1016/j.cmet.2009.12.009

Bailey AJ, Knott L (1999) Molecular changes in bone collagen in osteoporosis and osteoarthritis in the elderly. Exp Gerontol. doi:10.1016/S0531-5565(99)00016-9

Baker DJ, Childs BG, Durik M, Wijers ME, Sieben CJ, Zhong J, Pezeshki A (2016) Naturally occurring p16Ink4a-positive cells shorten healthy lifespan. Nature 530(7589):184-189
Bakker AD, Soejima K, Klein-Nulend J, Burger EH (2001) The production of nitric oxide and prostaglandin E2 by primary bone cells is shear stress dependent. J Biomech. doi:10.1016/S0021-9290(00)00231-1

Baron R, Kneissel M (2013) WNT signaling in bone homeostasis and disease: from human mutations to treatments. Nat Med 19:179-192

Barrès R, Yan J, Egan B, Treebak J, Rasmussen M, Fritz T, Zierath J (2012) Acute exercise remodels promoter methylation in human skeletal muscle. Cell Metab 15(3):405-411. doi:10.1016/j.cmet.2012.01.001

Bassey E, Rothwell M, Littlewood J, Pye D (1998) Pre-and postmenopausal women have different bone mineral density responses to the same high-impact exercise. J Bone Miner Res 13(12):1805-1813

Baxter-Jones ADG, Kontulainen SA, Faulkner RA, Bailey DA (2008) A longitudinal study of the relationship of physical activity to bone mineral accrual from adolescence to young adulthood. Bone 43(6):1101-1107. doi:10.1016/j. bone.2008.07.245

Boivin GY, Chavassieux PM, Santora AC, Yates J, Meunier PJ (2000) Alendronate increases bone strength by increasing the mean degree of mineralization of bone tissue in osteoporotic women. Bone. doi:10.1016/S87563282(00)00376-8

Bolam KA, Skinner TL, Jenkins DG, Galvão DA, Taaffe DR (2015) The osteogenic effect of impact-loading and resistance exercise on bone mineral density in middleaged and older men: a pilot study. Gerontology 62:22-32

Boreham CAG, McKay HA (2011) Physical activity in childhood and bone health. Br J Sports Med 45(11):877-879. doi:10.1136/bjsports-2011-090188

Boskey AL (2013) Bone composition: relationship to bone fragility and antiosteoporotic drug effects. BoneKEy Rep 2:447

Boskey AL, Coleman R (2010) Aging and bone. J Dent Res 89(12):1333-1348. doi:10.1177/0022034510377791

British Orthopaedic Association (2007) The care of patients with fragility fractures Blue Book. British Orthopaedic Association, London

Brotto M, Bonewald L (2015) Bone and muscle: interactions beyond mechanical. Bone. doi:10.1016/j.bone.2015.02. 010

Brunet A, Berger SL (2014) Epigenetics of aging and agingrelated disease. J Gerontol A 69(Suppl 1):S17-S20. doi:10.1093/gerona/glu042

Burge RT, Worley D, Johansen A, Bhattacharyya S, Bose U (2001) The cost of osteoporotic fractures in the UK: projections for 2000-2020. J Med Econ 4(1-4):51-62

Burr DB (1997) Muscle strength, bone mass, and Age-Related bone loss. J Bone Miner Res 12(10):1547-1551

Burr DB, Milgrom C, Fyhrie D, Forwood M, Nyska M, Finestone A, Simkin A (1996) In vivo measurement of human tibial strains during vigorous activity. Bone 18(5):405-410

Case N, Thomas J, Xie Z, Sen B, Styner M, Rowe D, Rubin J (2013) Mechanical input restrains PPAR $\gamma 2$ expression and action to preserve mesenchymal stem cell multipotentiality. Bone. doi:10.1016/j.bone.2012.08.122

Cedar H, Bergman Y (2009) Linking DNA methylation and histone modification: patterns and paradigms. Nat Rev Genet 10(5):295-304 
Chang G, Regatte R, Schweitzer M (2009) Olympic fencers: adaptations in cortical and trabecular bone determined by quantitative computed tomography. Osteoporos Int 20(5):779-785

Childs BG, Durik M, Baker DJ, Van Deursen JM (2015) Cellular senescence in aging and age-related disease: from mechanisms to therapy. Nat Med 21(12):1424-1435

Demontiero O, Vidal C, Duque G (2012) Aging and bone loss: new insights for the clinician. Ther Adv Musculoskelet Dis $4(2): 61-76$

Fonseca H, Moreira-Gonçalves D, Esteves JLS, Viriato N, Vaz M, Mota MP, Duarte JA (2011) Voluntary exercise has long-term in vivo protective effects on osteocyte viability and bone strength following ovariectomy. Calcif Tissue Int 88(6):443

Gardinier JD, Al-Omaishi S, Morris MD, Kohn DH (2016) PTH signaling mediates perilacunar remodeling during exercise. Matrix Biol 52-54:162-175. doi:10.1016/j. matbio.2016.02.010

Gardner JP, Li S, Srinivasan SR (2005) Rise in insulin resistance is associated with escalated telomere attrition. Circulation 111:2171-2177

Gaur T, Lengner CJ, Hovhannisyan H, Bhat RA, Bodine PVN, Komm BS, Lian JB (2005) Canonical WNT signaling promotes osteogenesis by directly stimulating Runx 2 gene expression. J Biol Chem 280(39):33132-33140. doi:10. 1074/jbc.M500608200

Gheno R, Cepparo JM, Rosca CE, Cotten A (2012) Musculoskeletal disorders in the elderly. J Clin Imaging Sci. doi:10.4103/2156-7514.99151

Gomez-Cabello A, Ara I, González-Agüero A, Casajus J, Vicente-Rodriguez G (2012) Effects of training on bone mass in older adults. Sports Med 42(4):301-325

Goodman CA, Hornberger TA, Robling AG (2015) Bone and skeletal muscle: key players in mechanotransduction and potential overlapping mechanisms. Bone 80:24-36

Govindaraju D, Atzmon G, Barzilai N (2015) Genetics, lifestyle and longevity: lessons from centenarians. Appl Transl Genomics 4:23-32. doi:10.1016/j.atg.2015.01.001

Gozansky W, Van Pelt R, Jankowski C, Schwartz R, Kohrt W (2005) Protection of bone mass by estrogens and raloxifene during exercise-induced weight loss. J Clin Endocrinol Metab 90(1):52-59

Guilluy C, Osborne LD, Landeghem LV et al (2014) Isolated nuclei adapt to force and reveal a mechanotransduction pathway in the nucleus. Nat Cell Biol 16:376-381

Haapasalo H, Kontulainen S, Sievanen H, Kannus P, Jarvinen M, Vuori I (2000) Exercise-induced bone gain is due to enlargement in bone size without a change in volumetric bone density: a peripheral quantitative computed tomography study of the upper arms of male tennis players. Bone 27(3):351-357. doi:10.1016/S8756-3282(00)003318

Hamilton CJ, Swan VJD, Jamal SA (2010) The effects of exercise and physical activity participation on bone mass and geometry in postmenopausal women: a systematic review of pQCT studies. Osteoporos Int 21:11-23

Hanley D, Adachi J, Bell A, Brown V (2012) Denosumab: mechanism of action and clinical outcomes. Int $\mathrm{J}$ Clin Pract 66(12):1139-1146
Heinonen A, Kannus P, Sievänen H, Oja P, Pasanen M, Rinne M, Vuori I (1996) Randomised controlled trial of effect of high-impact exercise on selected risk factors for osteoporotic fractures. Lancet 348(9038):1343-1347. doi:10. 1016/S0140-6736(96)04214-6

Hendrickx G, Boudin E, Van Hul W (2015) A look behind the scenes: the risk and pathogenesis of primary osteoporosis. Nat Rev Rheumatol 11(8):462-474

Henry YM, Fatayerji D, Eastell R (2004) Attainment of peak bone mass at the lumbar spine, femoral neck and radius in men and women: relative contributions of bone size and volumetric bone mineral density. Osteoporos Int 15:263-273

Hernandez CJ, Beaupré GS, Carter DR (2003) A theoretical analysis of the relative influences of peak BMD, age-related bone loss and menopause on the development of osteoporosis. Osteoporos Int 14:843-847

Hernlund E, Svedbom A, Ivergård M et al (2013) Osteoporosis in the european union: medical management, epidemiology and economic burden. Arch Osteoporos 8:1-136

Hind K, Burrows M (2007) Weight-bearing exercise and bone mineral accrual in children and adolescents: a review of controlled trials. Bone 40(1):14-27. doi:10.1016/j.bone. 2006.07.006

Hofbauer LC, Khosla S, Dunstan CR, Lacey DL, Spelsberg TC, Riggs BL (1999) Estrogen stimulates gene expression and protein production of osteoprotegerin in human osteoblastic cells. Endocrinology 140(9):4367-4370. doi:10.1210/endo.140.9.7131

Howe TE, Shea B, Dawson LJ, Downie F, Murray A, Ross C, Creed G (2011) Exercise for preventing and treating osteoporosis in postmenopausal women. Cochrane Database Syst Rev. doi:10.1002/14651858.CD000333.pub2

Hughes DE, Dai A, Tiffee JC, Li HH, Mundy GR, Boyce BF (1996) Estrogen promotes apoptosis of murine osteoclasts mediated by TGF-beta. Nat Med 2(10):1132-1136

Ireland A, Rittweger J (2017) Exercise for osteoporosis: how to navigate between overeagerness and defeatism. J Musculoskelet Neuronal Interact 17(3):155-161

Ireland A, Maden-Wilkinson T, McPhee J, Cooke K, Narici M, Degens H, Rittweger J (2013) Upper limb muscle-bone asymmetries and bone adaptation in elite youth tennis players. Med Sci Sports Exerc 45(9):1749-1758. doi:10. 1249/MSS.0b013e31828f882f

Ireland A, Muthuri S, Rittweger J, Adams JE, Ward KA, Kuh D, Cooper R (2017) Later age at onset of independent walking is associated with lower bone strength at fractureprone sites in older men. $J$ Bone Miner Res 32(6):1209-1217. doi:10.1002/jbmr.3099

Jha S, Wang Z, Laucis N, Bhattacharyya T (2015) Trends in media reports, oral bisphosphonate prescriptions, and hip fractures 1996-2012: an ecological analysis. J Bone Miner Res 30(12):2179-2187. doi:10.1002/jbmr.2565

Ji M, Yu Q (2015) Primary osteoporosis in postmenopausal women. Chronic Dis Transl Med 1(1):9-13. doi:10.1016/ j.cdtm.2015.02.006

Judex S, Gupta S, Rubin C (2009) Regulation of mechanical signals in bone. Orthod Craniofac Res 12(2):94-104. doi:10.1111/j.1601-6343.2009.01442.x

Jung M, Pfeifer G (2015) Aging and DNA methylation. BMC Biol 13:1-8 
Justesen J, Stenderup K, Ebbesen E, Mosekilde L, Steiniche T, Kassem M (2001) Adipocyte tissue volume in bone marrow is increased with aging and in patients with osteoporosis. Biogerontology 2(3):165-171

Karasik D, Rivadeneira F, Johnson ML (2016) The genetics of bone mass and susceptibility to bone diseases. Nat Rev Rheumatol 12:323-334

Kelley GA, Kelley KS, Kohrt WM (2013) Exercise and bone mineral density in premenopausal women: a meta-analysis of randomized controlled trials. Int $\mathrm{J}$ Endocrinol 2013:741639. doi:10.1155/2013/741639

Klein-Nulend J, Bakker AD (2007) Osteocytes: mechanosensors of bone and orchestrators of mechanical adaptation. Clin Rev Bone Miner Metab 5(4):195-209

Klop C, van Staa TP, Cooper C, Harvey NC, de Vries F (2017) The epidemiology of mortality after fracture in england: variation by age, sex, time, geographic location, and ethnicity. Osteoporos Int 28:161-167

Kobayashi K, Nojiri H, Saita Y et al (2015) Mitochondrial superoxide in osteocytes perturbs canalicular networks in the setting of age-related osteoporosis. Sci Rep 5(9148):1-11

Korvala J, Jüppner H, Mäkitie O, Sochett E, Schnabel D, Mora S, Cole WG (2012) Mutations in LRP5 cause primary osteoporosis without features of OI by reducing wnt signaling activity. BMC Med Genet 13(1):26

Krishnan V, Bryant HU, Macdougald OA (2006) Regulation of bone mass by wnt signaling. J Clin Investig 116(5):1202-1209. doi:10.1172/JCI28551

Kryston TB, Georgiev AB, Pissis P, Georgakilas AG (2011) Role of oxidative stress and DNA damage in human carcinogenesis. Mutat Res 711(1-2):193-201. doi:10. 1016/j.mrfmmm.2010.12.016

Lindholm ME, Marabita F, Gomez-Cabrero D, Rundqvist H, Ekström T, Tegnér J, Sundberg CJ (2014) An integrative analysis reveals coordinated reprogramming of the epigenome and the transcriptome in human skeletal muscle after training. Epigenetics 9(12):1557-1569. doi:10.4161/ 15592294.2014.982445

Lindsay R, Krege J, Jin L, Stepan J (2016) Teriparatide for osteoporosis: importance of the full course. Osteoporos Int 27:2395-2410

Lips P, Hosking D, Lippuner K, Norquist JM, Wehren L, Maalouf G, Chandler J (2006) The prevalence of vitamin D inadequacy amongst women with osteoporosis: an international epidemiological investigation. J Intern Med 260(3):245-254. doi:10.1111/j.1365-2796.2006.01685.x

Liu-Ambrose TY, Khan KM, Eng JJ, Heinonen A, McKay HA (2004) Both resistance and agility training increase cortical bone density in 75-to 85-year-old women with low bone mass: a 6-month randomized controlled trial. J Clin Densitom 7(4):390-398

López-Otín C, Blasco MA, Partridge L, Serrano M, Kroemer G (2013) The hallmarks of aging. Cell 153(6):1194-1217. doi:10.1016/j.cell.2013.05.039

Loprinzi PD et al (2015) Movement-based behaviors and leukocyte telomere length among US adults. Med Sci Sports Exerc 47:2347-2352

Lu B, Chen H, Lu H (2012) The relationship between apoptosis and aging. Adv Biosci Biotechnol 3:705-711
Lundberg P, Lundgren I, Mukohyama H, Lehenkari PP, Horton MA, Lerner UH (2001) Vasoactive intestinal peptide (VIP)/pituitary adenylate cyclase-activating peptide receptor subtypes in mouse calvarial osteoblasts: presence of VIP-2 receptors and differentiation-induced expression of VIP-1 receptors. Endocrinology 142(1):339-347. doi:10.1210/endo.142.1.7912

MacKelvie KJ, Khan KM, McKay HA (2002) Is there a critical period for bone response to weight-bearing exercise in children and adolescents? A systematic review. $\mathrm{Br} \mathrm{J}$ Sports Med 36(4):250-257 ; discussion 257

Maddalozzo G, Snow C (2000) High intensity resistance training: effects on bone in older men and women. Calcif Tissue Int 66:399-404

Mann V, Huber C, Kogianni G, Jones D, Noble B (2006) The influence of mechanical stimulation on osteocyte apoptosis and bone viability in human trabecular bone. J Musculoskelet Neuronal Interact 6(4):408-417

Manolagas SC (2010) From estrogen-centric to aging and oxidative stress: a revised perspective of the pathogenesis of osteoporosis. Endocr Rev 31:266-300

Manolagas SC, Parfitt AM (2010) What old means to bone. Trends Endocrinol Metab 21(6):369-374

Marcu F, Bogdan F, Mutiu G, Lazar L (2011) The histopathological study of osteoporosis. Rom J Morphol Embryol 52(1):321-325

Marie PJ (2007) Strontium ranelate: new insights into its dual mode of action. Bone 40(5, Supplement 1):S5-S8. doi:10. 1016/j.bone.2007.02.003

Marshall D, Johnell O, Wedel H (1996) Meta-analysis of how well measures of bone mineral density predict occurrence of osteoporotic fractures. BMJ (Clin Res Ed) 312(7041):1254-1259

Martin George M, Junko Oshima (2010) Lessons from human progeroid syndromes. Nature 408:263-266

Martyn-St JM, Carroll S (2010) Effects of different impact exercise modalities on bone mineral density in premenopausal women: a meta-analysis. J Bone Miner Metab 28(3):251-267

McCalden RW, McGeough JA, Barker MB, Court-Brown CM (1993) Age-related changes in the tensile properties of cortical bone. The relative importance of changes in porosity, mineralization, and microstructure. J Bone Joint Surg 75(8):1193-1205

Meyer U, Ernst D, Zahner L, Schindler C, Puder JJ, Kraenzlin M, Kriemler S (2013) 3-year follow-up results of bone mineral content and density after a school-based physical activity randomized intervention trial. Bone 55(1):16-22. doi:10.1016/j.bone.2013.03.005

Milgrom C, Finestone A, Simkin A, Ekenman I, Mendelson S, Millgram M et al (2000) In-vivo strain measurements to evaluate the strengthening potential of exercises on the tibial bone. J Bone Joint Surg 82(4):591-594

Moustafa AA (2014) Motor and cognitive changes in normal aging. Front Aging Neurosci 6(331):1-3

Nogueira RC, Weeks BK, Beck BR (2014) Exercise to improve pediatric bone and fat: a systematic review and metaanalysis. Med Sci Sports Exerc 46:610-621

Neer RM, Arnaud CD, Zanchetta JR, Prince R, Gaich GA, Reginster J, Mitlak BH (2001) Effect of parathyroid hormone (1-34) on fractures and bone mineral density in 
postmenopausal women with osteoporosis. N Engl J Med 344(19):1434-1441. doi:10.1056/ NEJM200105103441904

Niccoli T, Partridge L (2012) Ageing as a risk factor for disease. Curr Biol 22(17):R741-R752. doi:10.1016/j.cub. 2012.07.024

NICE (2012) Osteoporosis: assessing the risk of fragility fracture. NICE, London

Nielsen BR, Linneberg A, Bendix L, Harboe M, Christensen K, Schwarz P (2015) Association between leukocyte telomere length and bone mineral density in women 25-93 years of age. Exp Gerontol 66:25-31. doi:10.1016/ j.exger.2015.04.004

Panula J, Pihlajamäki H, Mattila VM, Jaatinen P, Vahlberg T, Aarnio P, Kivelä S (2011) Mortality and cause of death in hip fracture patients aged 65 or older-a population-based study. BMC Musculoskelet Disord 12(1):1

Pazianas M (2015) Anabolic effects of PTH and the 'anabolic window'. Trends Endocrinol Metab 26(3):111-113. doi:10.1016/j.tem.2015.01.004

Polidoulis I, Beyene J, Cheung AM (2011) The effect of exercise on pQCT parameters of bone structure and strength in postmenopausal women-a systematic review and meta-analysis of randomized controlled trials. Osteoporos Int 23:39-51

Quarles LD (2012) Role of FGF23 in vitamin D and phosphate metabolism: implications in chronic kidney disease. Exp Cell Res 318(9):1040-1048. doi:10.1016/j.yexcr.2012.02. 027

Recker RR, Davies KM, Hinders SM et al (1992) Bone gain in young adult women. JAMA 268:2403-2408

Regard JB, Zhong Z, Williams BO, Yang Y (2012) Wnt signaling in bone development and disease: making stronger bone with wnts. Cold Spring Harbor Perspect Biol. doi:10. 1101/cshperspect.a007997

Riggs BL, Melton LJ, Robb RA, Camp JJ, Atkinson EJ, Peterson JM, Khosla S (2004) Population-based study of age and sex differences in bone volumetric density, size, geometry, and structure at different skeletal sites. J Bone Miner Res 19(12):1945-1954. doi:10.1359/jbmr.040916

Ritschka B, Storer M, Mas A, Heinzmann F, Ortells MC, Morton JP, Keyes WM (2017) The senescence-associated secretory phenotype induces cellular plasticity and tissue regeneration. Genes Dev 31(2):172-183. doi:10.1101/gad. 290635.116

Rönn T, Volkov P, Davegårdh $\mathrm{C}$ et al (2013) A six months exercise intervention influences the genome-wide DNA methylation pattern in human adipose tissue. PLoS Genet 9(6):e1003572

Ross TD, Coon BG, Yun S, Baeyens N, Tanaka K, Ouyang M, Schwartz MA (2013) Integrins in mechanotransduction. Curr Opin Cell Biol 25(5):613-618. doi:10.1016/j.ceb. 2013.05.006

Schaffler MB, Cheung W, Majeska R, Kennedy O (2014) Osteocytes: master orchestrators of bone. Calcif Tissue Int 94(1):5-24

Sernbo I, Johnell O (1993) Consequences of a hip fracture: a prospective study over 1 year. Osteoporos Int 3(3):148-153
Sharkey NA, Ferris L, Smith TS, Matthews DK (1995) Strain and loading of the second metatarsal during heel-lift. J Bone Joint Surg 77(7):1050-1057

Shimizu I, Yoshida Y, Suda M, Minamino T (2014) DNA damage response and metabolic disease. Cell Metab 20:967-977

Sibonga JD (2013) Spaceflight-induced bone loss: is there an osteoporosis risk? Curr Osteoporos Rep 11(2):92-98

Sievänen H, Heinonen A, Kannus P (1996) Adaptation of bone to altered loading environment: a biomechanical approach using X-ray absorptiometric data from the patella of a young woman. Bone. doi:10.1016/8756-3282(96)00111-1

Sims NA, Martin TJ (2014) Coupling the activities of bone formation and resorption: a multitude of signals within the basic multicellular unit. BoneKEy Rep 3:481

Specker BL, Wey HE, Smith EP (2010) Rates of bone loss in young adult males. Int J Clin Rheumtol 5:215-228

Styner M, Thompson WR, Galior K, Uzer G, Wu X, Kadari S, Rubin J (2014) Bone marrow fat accumulation accelerated by high fat diet is suppressed by exercise. Bone. doi: 10 . 1016/j.bone.2014.03.044

Svedbom A, Hernlund E, Ivergard M et al (2013) Osteoporosis in the european union: a compendium of country-specific reports. Arch Osteoporos 8:137

Tatsumi S, Ishii K, Amizuka N, Li M, Kobayashi T, Kohno K, Ikeda K (2007) Targeted ablation of osteocytes induces osteoporosis with defective mechanotransduction. J Endocrinol. doi:10.1016/j.cmet.2007.05.001

Tu X, Delgado-Calle J, Condon KW et al (2015) Osteocytes mediate the anabolic actions of canonical wnt/ $\beta$-catenin signaling in bone. PNAS 20:E478-E486

Tveit M, Rosengren B, Nilsson J, Karlsson M (2015) Exercise in youth: high bone mass, large bone size, and low fracture risk in old age. Scand $\mathrm{J}$ Med Sci Sports 25(4):453-461

Udagawa N, Takahashi N, Yasuda H, Mizuno A, Itoh K, Ueno Y, Suda T (2000) Osteoprotegerin produced by osteoblasts is an important regulator in osteoclast development and function. Endocrinology 141(9):3478-3484. doi:10. 1210/endo.141.9.7634

UK Office for National Statistics (2016) Mid-2015 population estimates. UK Office for National Statistics, London

Uusi-Rasi K, Kannus P, Cheng S, Sievänen H, Pasanen M, Heinonen A, Vuori I (2003) Effect of alendronate and exercise on bone and physical performance of postmenopausal women: a randomized controlled trial. Bone 33(1):132-143. doi:10.1016/S8756-3282(03)00082-6

Valdes A, Richards J, Gardner J, Swaminathan R, Kimura M, Xiaobin L, Spector T (2007) Telomere length in leukocytes correlates with bone mineral density and is shorter in women with osteoporosis. Osteoporos Int 18(9):1203-1210

Wall J, Chatterji S, Jeffery J (1979) Age-related changes in the density and tensile strength of human femoral cortical bone. Calcif Tissue Int 27(1):105-108

Warden SJ, Fuchs RK, Castillo AB et al (2007) Exercise when young provides lifelong benefits to bone structure andStrength. J Bone Miner Res 22:251-259

Warden SJ, Mantila Roosa SM, Kersh ME, Hurd AL, Fleisig GS, Pandy MG, Fuchs RK (2014) Physical activity when young provides lifelong benefits to cortical bone size and 
strength in men. Proc Natl Acad Sci USA 111(14):5337-5342. doi:10.1073/pnas.1321605111

Weaver CM, Gordon CM, Janz KF, Kalkwarf HJ, Lappe JM, Lewis R, Zemel BS (2016) The national osteoporosis foundation's position statement on peak bone mass development and lifestyle factors: a systematic review and implementation recommendations. Osteoporos Int 27:1281-1386. doi:10.1007/s00198-015-3440-3

Weinstein SL (2016) The burden of musculoskeletal conditions. J Bone Joint Surg 98:1331. doi:10.2106/JBJS.16. 00595

Weitzmann MN, Pacifici R (2006) Estrogen deficiency and bone loss: an inflammatory tale. J Clin Invest 116(5):1186-1194. doi:10.1172/JCI28550

WHO (2015) Ageing and health. Fact Sheet 404. http://www. who.int/mediacentre/factsheets/fs404/en/
Wiley CD, Velarde M, Lecot P et al (2016) Mitochondrial dysfunction induces senescence with a distinct secretory phenotype. Cell Metab 23:303-314

Woo S, Hellstein JW, Kalmar JR (2006) Systematic review: bisphosphonates and osteonecrosis of the jaws. Ann Intern Med 144(10):753-761

Yin X, Wang X, Hu X, Chen Y, Zeng K, Zhang H (2015) ER $\beta$ induces the differentiation of cultured osteoblasts by both wnt/ $\beta$-catenin signaling pathway and estrogen signaling pathways. Exp Cell Res 335(1):107-114. doi:10.1016/j. yexcr.2015.04.020

Zhang H, Ryu D, Wu Y (2016) $\mathrm{NAD}^{+}$repletion improves mitochondrial and stem cell function and enhances life span in mice. Science 352:1436-1443 